\title{
The Estimation of the Alternatives that Improve the System of Trade of the Agricultural Products in Albania
}

\author{
Edlira Llazo \\ PhD Candidate, "Aleksander Moisiu" University, Durres, Albania \\ Bussines Faculty, Marketing Department, Durres, Albania \\ e-mail: llazo@hotmail.it
}

\section{Doi:10.5901/mjss.2013.v4n3p295}

\begin{abstract}
Agriculture is one of the most important sectors in the Albanian Economy even though it does not have a contribution is one of the most important in the Albanian economy even though it does not contribute to the brute domestic product. The reasons are different and various beginning with the from the farm and non function systems of the agricultural trade .this research intends to analyze problems in the current system of the agricultural markets in Albania and to propose alternatives that improve this system in order to raise the integration of the farmers towards the farmers in the market and at the same time the increase of the rural incomes. The area of study is in Tirana, Durres and Lushnje as representative zones of the sector according to the amount that they are included in the albanian agriculture. The datas used are secondary ones as well as the focus groups with the farmers. From the results is concluded that the level of the integration towards markets is low and the proposal for the establishment of the agencies in the agricultural market is considered as an alternative that improves the integration of the farmers towards the market and at the same time increases their incomes.
\end{abstract}

Keywords: agriculture, farmer, market, integration, agency of the agricultural market.

\section{Introduction}

Agriculture is and has always been and will remain for a long time one of the sectors most important in the Albanian economy. This sector contributes in more than $20 \%$ of the general national product and in this sector are employed more than half of the working forces of the Albania. Albania possesses not too much agricultural land, almost $25 \%$ of the Albanian territory and has got the least quantity of land per person in Europe, almost $1 \mathrm{dn} /$ person.

There are a lot of various projects and programs carried out for the rehabilitation of the rural and agricultural infrastructure in the country. There has been a lot of investments and persuasion towards the development of the agriculture but the situation in the agricultural sector is not at that degree to fulfill the needs of the consumers and the development of the industry is not at that state to compete in the national markets.

Considering the development of the albanian economy in general and that of the food and agriculture sector in particular, it is obviously noticed that in Albania it is necessary to improve the systems of the agricultural product for more integration of the farmers with the markets and this requires an analysis of the structure of the product in the farm and the factors that customize as well as the definition of the effects in the improvement of the systems of the agricultural products in the increase of of the level of integration of the farmers with the markets.

A great importance in this matter is considered the analysis and the evaluation of the alternatives that improve the system of the agricultural products trade in Albania by analyzing and evaluation of the actual state of the way of organizing and functioning of the markets of the agricultural products by defying the role and the function of the wholesale market and the role of the participation of the farmers in the markets.

At the same time the definition of the alternatives that control and reduce the risk of the markets of the trade of the agricultural products and the defying of the problems of the ddistribution of the sales of the products ,livestock and the storage of the products, sale contracts and the vertical integration and moreover the advisee to improve the state, these problems are actual issues for the albanian agriculture.

\section{Literature Review}

The reconsidering of the literature for the topic "Analysis and study of the alternatives that improve the system of the 
marketing of agricultural products " intends to search in connection with the theory and the current literature that exists owing to the issue that is thought to be studied and at the same time to define the methodology in this research.

What is important to be analyzed is the fact that in the albanian language the are not too many publications and information available, despite the university publications.

At the same time in the foreign literature there are materials to be studied, but not too many practical materials and it is difficult to be applied and to be used in the conditions of our country , because these publications are based on the researches performed in the developed countries where the level of the farming and marketing of the agricultural products is very developed or they may be publications or researches too much specific and they are too far from the albanian reality.

In the publication (Kolnikaj,P.,Vërçuni, A. dhe Male B., "The marketing of the agriculutral products " Pg. 215 $227)$ in connection with this topic is pointed out : "the vertical cooperation and the specialization of the production are essential for the efficiency of the productive subjects and are worked so well , and this has to do with the cost in general and the fixed cost, variable and that of average in particular. A greta important is considered the diverse of the overworking industry and the decentralization of the food products and agricultural markets. As a result of this there are some factors that have got a great influence :

- The system of transport

- Communication

- The systems of storage, classification and standardization

- Livestock

- The development to a great degree of the sales

- So all these factors together with the vertical and horizontal integration have got a great influence in the process."

For this issue in (Knutson,R., Penn,J.P. and Boehm,W. " Agricultural and food policy") is clearly defined the role of the trade for the development of the economy and the agricultural sector and agribusiness.(Knutson,R., Penn,J.P. and Boehm,W. " Agricultural and food policy" Pg. 124 - 145), the existence and the establishment of the appropriate policy of the agricultural prizes (Knutson,R., Penn,J.P. and Boehm,W. " Agricultural and food policy" Pg. 306 - 325), the proper conditions of feeding, food security and the quality of the foods.

(Knutson,R., Penn,J.P. and Boehm,W. " Agricultural and food policy" 326 - 357) and the impact of the agricultural policy and food in the a sector of agribusiness (Knutson,R., Penn,J.P. and Boehm,W. " Agricultural and food policy" Pg, 397 - 422). And the materials "Agricultural and Food Policy" and "Analysis of Agricultural and Food Policy', publications of FAO-s provide the same concept theoretical and practical.

At the same time for this issue the publication of Beierlein,J., Woolverton, M., Prentice Hall.(1991) "Agribusiness marketing the management perspective", gives a better actual point of view for the role of the marketing in the agribusiness system (Beierlein,J., Woolverton, M., Prentice Hall.(1991) "Agribusiness marketing the management perspective" Pg, 22). The producer in the farm level the intermediate for the wholesale market and special for the working centers, up to the ultimate consumer make such questions :

- What will produce?

- How much will produce?

- When will produce?

- Where will produce?

- Who they will produce for?

At the same time in this publications there will be expressed in. A clear way the advantages of the specialization and the trade of the agricultural products.

(Beierlein,J., Woolverton, M., Prentice Hall.(1991) "Agribusiness marketing the management perspective" Pg, 24), specifying that: "the specialization of the work brings about a rise in the total product, the marketing of the specialized production creates conditions to produce beyond the personal needs and this brings chances or opportunities to require in the market for other goods that the farmers need and the manufacturers of the agribusiness but these products are not produced by them".

Furthermore in this publication are introduced "the ways of using money and the liquidations to lessen the exchange of the products, the development of the centered markets that make it easier the market, and are markets that ask for people that have to get involved in the management of these markets and this causes the ned for intermediates that are specialized in the market but not in consumption" (Beierlein,J., Woolverton, M., Prentice Hall.(1991) "Agribusiness marketing the management perspective" Pg, 24 - 25). 
"Three main functions of the marketing that are functions of exchange, physical and lessening. These are separated in other functions that are ordered in this way :

- The exchange function - buying, selling

- Physical function - storage, transport, working

- Lessening functions - grading of the standards financial taking into risk and the information of the trade. can be :

In this publication are given some strategies that the farmers must follow to improve their profits. These strategies

1. The analysis of the market to notice what are the required products

2. Buying of the inputs with lower prizes

3. Creation of the immediate functions like storage, transport and finance

4. Selling in the right time for a better price

5. Offer of the accommodation when they are needed (Beierlein,J., Woolverton, M., Prentice Hall.(1991) "Agribusiness marketing the management perspective" $\mathrm{f}, 121$ )

On the publication (Kolnikaj,P., Vërçuni, A. and Male B., "The marketing of the agricultural products ", f 238 - 241) is pointed out that : "the cooperatives of the marketing of buying of the service and the working are the best ways in connection with the topic.

- These four types of cooperatives can be :

- Independent local associations

- Federated associations

- Central cooperative associations

- Mixed associations "

The analyse and the evaluation of the current state and the way of the organization and function of the markets of the agricultural products.

\subsection{The role and the functions of the markets .}

\subsubsection{Wholesale selling}

The traders of the wholesale markets are traders that sell goods to those people that buy them for reselling till to the last consumer . They are situated in big cities and in general sell a greta amount of products .

These wholesale traders are separated into two groups:

1. The traders that sell only fresh products of the fruit and vegetables imported during all the year - and those that tend to have movements of their goods (Circulation) and those that sell a great amount of goods mostly imported and often go themselves to make the transportation of different products. Some of them have warehouses but too often use the lorries with cooling appliances to store and keep them fresh.

2. Those that perform the trade of the imported goods not seasonal and domestic produced goods Which are found later and tend to sell them with a lower circulation. The domestic productions are mostly sold in the direct productive places from the farmers or the trades of the wholesale and later are transported in big cities and specifically are sold to the traders that buy with small amounts. In some cases the farmers send their products directly to the traders who sell with great amounts. Most of the wholesale traders do not have places for the storage of their goods, but they sell their goods direct to the lorries. The wholesale traders usually buy and sell in cash, but some others offer in the form of loan , for example "the payment is performed in the next supplying".

In Albania there are 13 agribusiness markets, that work out as trade centers of wholesale markets from these :

1. Six (6) markets are in the complete function (Lushnje, Vlorë, Berat, Korçë, Shkodër and Kukës)

2. Five markets (5) which are actually in function (Dibër, Lezhe, Has, Mat and Gjirokastër) with the 100\% public capital (based on the Law Nr. 9901 date 14.04.2008 "For the traders and the marketing associations ")

3. One (1) market with the Public-private capital (in Tirana) and a market with a completely private capital (Fier)

The trade of the fruit and vegetables is performed mostly in 11 trades or markets that function like wholesale markets and as other minor markets . 
The wholesale markets gather and distribute the most part of the domestic products and those that are imported according to the season of the production. In the marketing of the domestic vegetables marketing of the vegetables the main part is that of Lushnje with almost 6000 tones of the traded vegetables in a year from which almost 80percent of the inner product (30 percent of the total product ).

In the fruit market produced in Albania the main role is played in the markets of Lushnja, Korca and Tirana.

Nearly all these markets function like trade areas and to not accomplish the necessary conditions for the storage, classification and the packing of the products before selling them. At the same time they do not perform contract cooperation with the producers.

By means of an information system from these markets are taken every day the prizes of the products that are sold and bought, which are announced in all the markets.

The increase of the number of supermarkets these latest years have caused to create a phenomena that the trades are no more considered as the only trades that control the distribution of the fruit and vegetables, because the supermarkets are establishing contracts direct ones with the productive farmers getting the product direct from the farm.

\subsubsection{The minor trades}

In general every city has got its own minor trades that are mostly investments public ones in the local state. In these markets most of the farmers are specialized for the marketing of the agricultural and livestock products. They are supplied by the wholesale traders, especially importers and from the farmers in the direct way (this has not to do with the main characteristics ). Only a small number of farmers have got their places of selling and buying in the minor markets. these farmers that are independent to sell in different inappropriate places, especially by means of the main roads of the cites. It is typical the selling of the livestock products, mainly milk.

At the same time there is a small number of farmers that posses shops in the cities, where they sell and buy their products. An important phenomenon is the opening of some shops, especially in Tirana Durres and Korce etc. where the citizens have achieved to cooperate with some farmers for the supplying with agricultural and livestock products almost every day. But this phenomenon as it seems remains limited by the reciprocal trust and not supported by the contract.

All the minor markets as in the case of the wholesale markets function mainly in places where there is marketing and do not fulfill the necessary conditions for storage, standardization or the pa king of the products before their marketing. At the same time they do not perform contractual relationships with the producers.

\section{The Methodology of the Research}

The main objective of the research is the identification and the evaluation of the possible alternatives of development, organization and well functioning of the systems of the agricultural markets, in order to grow the level of integration of the farmers in them and the rise of the rural incomes in Albania .

The evaluation of the actual systems in the organizations of the agricultural markets and the factors that customize them. To fulfill this objective :

- They will identify the factors that customize the current structures of the organization of the agricultural markets and the needs to improve them .

- They will identify and evaluate the ways of organization and functioning of the wholesale and minor trades of the agricultural products .

The identification of the alternatives that increase the participation of the farmers in the markets and the growth of the level of the commercialization of the agriculture.

The research hypothesis are :

1. The systems of the agricultural product in Albania are characterized by the weak connections with the trades as a result of the problems that have to do with the kind and level of production as well as with the organization and well functioning of the markets.

2. In Albania the connection between the trade of the agricultural products and the marketing of these products is still weak and unavailable and undeveloped. The problems have to to with the production, working, storage, standards, trade and marketing.

3. There are possibilities for the strengthening of the connection between the agricultural marketing and the growth of the agricultural product in the way that this connection becomes stable and to guarantee the parallel 
development between the agricultural product as a support for the economy and the domestic trades and those for export.

To verify the hypothesis the area of study is located in three regions.(Tirane, Lushnje and Durres). The in formation that make it possible to achieve this research will be ensured by the other various resources like this :

- The data from the official institutions and the other sources that are independent.

- Interviews with experts and specialists of the agricultural field in the respective regions

- Interviews of the farmers in the focus groups etc.

In the planned interview with the specialists of the Directory of Agriculture ,Food and the Defense of the Consumers in Tirana there are participating specialists of the agriculture that are representative of different regions of Tirana .

The discussion was focused mainly on the issue of the organization of the farmers in the associations, the state of the markets wholesale and minor ones of the agricultural and livestock products and the way of the out coming of the farmers in the markets.

From the topic it is resulted that even though in the market there are found a great amount of farmers, less than half of them are participating for profit and to enlarge their activity. According to the specialists about one third $1 / 3$ of the farmers are found in the market every day. In the villages of Tirana there are shortage of frozen capacities and storage capacities.

The wholesale traders are more connected with the import of the agricultural products and livestock products rather than the farmers and this results from the lack of individual offer of the farmers and the lack of their organization in the producers associations. Another weak point in this direction is also the lack of standardization, selection, gradation of the products.

According to the specialists in Tirana there are only 3 specialized shops that belong to the farmers, where they sell fruits, vegetables and meat.

In general the farmers possess transport equipment but only a few of them have transporting equipments for the farming products even though the farmers have production and send them to the market.

According to the specialist very few farmers sell in wholesale and the wholesale market as a phenomenon is noticed in the peak of the production. In this period of the peak of production the farmers notice the competition of the import and make the prizes lower beyond the real cost of the production, where most of the farmers do not calculate the wage of their workday and the wage of the workday of the other members of the family.

At the same time in connection with this issue and the trade of the products in the market, it is noticed that the main work in the farm and the marketing is performed be the main member of the family, and this phenomenon explains the reasons why he is not all the time during the year from the farm and the works of the farms (because he spends most of the time selling ), causing problems in the management of the farm and this can be eliminated from the the separation of the work.

The interview with focus groups was focused mainly on the problem of the seasonal agricultural working ,the introduction of the farmers in the market ,the possibility of the creation of the associations of the farmers .

From the discussion is resulted that the farmers introduce to the market but not every day . On average they introduce to the market $9-11$ days in a month They live next to the communication streets that connect Tirana to Durres and in general they use transport equipment by hiring them to commute in the city and to contact with the possible traders.

The farmers agreed that in the villages there are lacks of storing and frozen capacities.

They are in contact with the wholesale traders in the city but they do not make contacts with them. The farmers were aware of the profits that were created as a result of the production, marketing, working and purchase of the common agricultural inputs but no one was bound to cooperate with the others to start the creation or the organization of an association.

No one of them has accomplished the gradation, standardization and the selection of the products even though they know much better from the technical point of view. When they were asked why they do not perform these processes they answered that as a result of the selling of the products there is no reason to spare time for these processes.

All of them had transport appliances of the car type and only one had an appropriate mean of the transport available to distribute the farming products. In the area where these farmers live there is only one that gathers the milk and worked it out and all the others ingredients like country cheese, butter that is marketing in this area.

When they were asked at what degree that can buy the inputs for which they have come to the center they answered that they knew quite well what are the amounts of the inputs that should be used in the farm according to the 
agricultural cultures, but they have never had for about $7-8$ latest years the possibility to fulfill in scientific way the needs of the production with chemicals, pesticides, herbicide and fungicide and the agricultural machinery, things that have influenced in the incomes of the farm .

\section{The alternatives of the improvements of the system of the trades and agricultural marketing in Albania.}

For the creation of the conditions of the agricultural and livestock productions ,to face as. Much as possible the demand and the offer , for the separation of the work in general and the separation of the work in the sector of the agriculture and that of trade in particular, it is necessary that the rural trades can be created and managed according to the modern model.

\subsection{Agency of the Agricultural Market}

To have a good way for the creation of the functions for which they are built the agricultural and rural trades, it is necessary to create responsible and effective organisms. A kind of organism is the Agency of the Agricultural Market (AAM) which as it is shown from the experience of other countries, involving here even other eastern countries ,that starts the way of the economy of the market like in Albania, and there are created conditions suitable ones for facing the the offer and demand for the agricultural products and livestock ones and aslo the inputs of agricultural services.

There are some markets that do not fulfill the facing conditions of the demand and offer and the physical, technical shortage in the current trades, together with the other political, economical social and cultural conditions and these have caused the control of the prizes of the agricultural and livestock and food products with the agricultural raw material to be checked from the spontaneous market. This phenomenon is associated with the limitation and the prevention of the subventions, the growth of the competitiveness from the foreign markets ,the weakness of the connection between the country with the working industry, the liberalization of the prizes, the creation of the monopoles in the marketing of the inputs and the outputs etc, and this has caused that the agriculture can be realized in the low levels of the incomes.

This has resulted that the usage of the agricultural inputs for surface unit from the part of the farmers to be lowered drastically.

According to the official data $30 \%$ of the surface planted with corn, sweet corn, potatoes and vegetables etc, it covers the necessary minimum of the azoic pesticides and only $15 \%$ of them involves the minimal needs for phosphoric pesticides. Only in the main plants of the fields the loss of the misusage of the pesticides get to $40 \mathrm{ml}$ dollars according to the calculations of the research accomplished by the OECD before some years. In these conditions where the agricultural markets are unstable And are developed in the organisms that lead and protect the agricultural product and systemize the agricultural and rural markets. This objective is accomplished by the Agency of the Agricultural Market(AAM).

This agency can have the main objective the stabilization of the markets of the products of the farms and the protection of the incomes from the agriculture. According to the experience of the other countries are created possibility that the agency can manage and the state food storage. AAM can have the larger autonomy for the interference in the agricultural markets and in the accomplishment of the state policies in this direction. The basic characteristic for the activity of AAM is the fact that it should intervene in the market by means of the mechanisms of the market, by the support and the regulation of the demand and the offer, instead of the usage of the channels and the administrative mechanisms. Based on official policies it should decide for every season the production of the services and for the products that will be considered necessary ,the minimum prize for the stabilization of the market prize.

The most important functions of AAM can be :

- The intervention in the purchase of the agricultural and food products to store or to sell in the inner markets or foreign ones, with the intention to achieve the stabilization of the prizes in the agricultural and livestock products.

- The accumulation of the most part of resources of the agricultural and livestock products and the management of the state resources of the food, the amount of which can be defined with the VKM (Decision of the Ministry of Council), in cooperation with the AAM.

- The support of the new firms that deal with the marketing of the products that come from the agriculture, mainly by means of the insurance of the loans, as a guarantee for the purchase the storage and export of the finished products in the market. 
- The analysis and the prediction of the problems that are connected with the markets of the agricultural products . The collection of the data ,the conception of the proposals and the initiatives for the development of the market infrastructure, and at the same time studies the improvement of the operations of the agricultural market constantly

According to the circumstances and the needs AAM can perform other functions from the juridical point of view those functions have to do with the purchase of inputs and outputs of the the agriculture.

AAM itself from the juridical point and financial point of view can be an organism that is financed from two main sources:

- The state budget, by means of the planning that is accomplished by the respective Ministry ;

- Its incomes taken from the efficient actions in the markets .

The agency has got the incomes and the expenses for the activity, for the purchase of the agricultural products and food ones, expenses for transport ,payment in advance for the products of other types expenses for the storage, for imports, for the effect of the resources state ones, subventions for the export of special products.

One of the main duties of the AAM is the stabilization of the prizes for the agricultural products. For this goal it can use the intervention in the prize policy. The interventions connected with the regulations of the prizes they do not have the administrative character, which means that they do not replace the regulations of the prizes by means of the demand and offer, they serve as surplus means, by regulating the lost balance for a period of time.

To achieve its objectives the agency can use two categories :

- The guaranteed minimum prizes

- The intervening prizes (Intervened, regulated)

The defining of the minimum of the prizes, as a level and according to the products (certainly can not be involved in all the products ), can be achieved with VKM from the state. But this can be under the control of the agency, currently the level of the prizes ,but not the nominating of the products, considering the resources in disposal, the prizes of the market and the costs of the products.

AAM can decide correctly ,keeping into contact with the representative of the farmers connected with the minimum prizes. After that the minimum prizes are introduced to the Council Of Ministry and after the approval there they become announced to the public. These prizes are available for a period of time almost one year and it is considered as the marketing period. This period can be from 1 March to 28 February of the next year.

The minimum prize defines the ceiling floor limit of the fluctuation of the prize of the market. The higher limit (boundary ) of the minimum prize is the prize of the input minimum (c.i.f. plus tariffs). The growth of the level of the minimum prize must be connected with the quantity tariffs over the inputs defined by the AAM.

To cover the minimum prize, the agencies should define the level of the intervening prizes that means they are higher than the minimum prizes.

The intervention in the market (to buy or to sell ) is accomplished to prevent the movement of the unexpected movement of the prizes of the farming products which have an influence direct on the incomes, and it is associated with unfair decisions .In this way they influence badly on the level of the national economy. Actually if the is no care for the farmer in the game of the market. There will be a great movement in the structure of planting lessening the surfaces and the production in the important cultures for the national economy and for the incomes of the farmers. In this way from one year to another there has been lessening of the planted and harvested fields with corn , aubergine etc.

The agency in general starts to interfere in the market for purchasing when the prize of the market is lower than the intervening prize and sell the storing products when the prize of the market is more or less than the market prize. As it can be seen a special importance is prevents the activity of the working industry and the commercial agriculture business after their operations and they depend on the loan for the purchase of the storing products. The high level of the intervening of the prizes are welcome from the farmers ,but they cause the high cost in different economical sectors, involving mainly the consumers and the producers that pay the taxes.

In the cases of the existence of the continuous overproduction, it means an unexpected offer ,the agency can lengthen its operations in the foreign market as well. The marketing exchanges must be in a way to emerge the observation of the defining average between the prizes of the domestic market and the foreign one. The higher level of the intervening prizes, with the non-real reference of the worldwide prizes prevents the improvement of the economic effectiveness of the agriculture and the foreign. As it is pointed out before and argued is is understood that the prizes of the market will move around the intervening of AAM it has a great influence on the stabilization of the prizes of the market and it brings about higher incomes for the farmers. The practical implementation of the activities in the regions 
,can be performed form different surfaces ,but connected with the agency with the official contracts. This lining of the problem needs improvements in connection with the banks , with the marketing infrastructure.

The state resources of the food products display the policy of insurance and prosperity. They include a defined item of the gathered products in the different state storehouses. In this way it should be seen and considered the reconstruction of the current Institutions of the State Resources, that now are almost passive .

Finally AAM is totally responsible for the food storages. The state storage are necessary in a situation when the insecurity in the agricultural production and this will bring about problems in the supplying with food. Considering the new political order towards the international market as well as the development of the domestic market of the food and not only it becomes necessary the system of the state resources, but it is required even the modernization of it and the procedure $s$ of the leadership. The involvement of it in the activity of AAM will influence positively in the fulfillment of these intentions.

From the primary tasks of AAM it available to mention the support of the initiatives and the different forms that have to do with the marketing of the farming products. And from these tasks are connected the activities dealing with the interventions in an indirect view. The activities connected with the intervention in the corn marketing can be :

- The authorization of the corn warehouses (when they are under the ownership of the currency of Agency), in order that their owners that profit preferential credit for the purchase and the storage of the corn.

- The purchase of the corn with the intervening prizes by means of the authorized line of the warehouses. In connection with the agents and agencies using the preferential loans.

- The payment for a part of the value of the product or the goods from the the producers themselves, according to the intervening prizes ,for the transportation in the nearest time.

- The guarantee of the bank loans for the borrowers especially for the selling of the corns.

As it is seen ,the authorization AAM of the different purchase firms and storage, will approve the condition to win the preferential loan. All these expenses that are connected with the authorizations, will be faced from its borrowers. The agency will require corn according to the conditions notified in the contract even when the prize in the market in under the intervening prize. In this case, the agency buys the product by paying a percentage plus over the prize of the intervening prize and even the expenses of the storage. The advanced payment will be performed for the producers that will store for a certain period of time and in a degree no more than $45 \%$ of their value of the stored product.

Besides these activities, AAM can do the task of import of the agricultural products direct by its own or by patterning the other companies. In this way a considerable amount of equipments can be supplied for the budget of the Agency. Within this agency Is taken by the marketing and trades sector which can have these tasks and responsibilities:

- The development and the implementation of the strategies and policies for the agromarketing sector and the agroprocessing, the analysis of the chains of the distribution of the agricultural products and food ones in the market .

- The identification of the needs and the emerge of the initiatives for investments in the industry of the agricultural processing for commercial activities in the two levels as beginner and that of the processed products. (subventions, loans etc).

- The support for the creation of the gathering centers and the improvement of the line of the distribution.

- The creation of a sameness of the legislation on the commercial standards with those of EU.

- The pursue of the ongoing of the reform in the agricultural sector, agroprocessing and the line of the marketing of the products.

- The preparation of the studies and the proposals leading to the growth of the effectiveness in the line of the marketing and the agroprocessing sector.

- The planning and the implementation of the budget plan in the marketing sector.

- The cooperation with the foreign donators in the marketing sector.

- The organization and the pursue of the national fairs and international ones in the field of agriculture ,food and the protection of the consumer.

- The suitability and the closeness of the legislation for marketing and agriprocessing according to the standards of EU.

- The coordination of the work with the technical leaders of the ministry and the projects with the foreign finance for the problems of the network of the marketing and the agroprocessing. 
- The pursue ,the analysis of the relationships, the exchanges commercial ones and the proper problematics with EU.

- The pursue the analysis of the relationships and the exchanges commercial ones and the proper problematic with CEFTA, EFTA, OBT etc.

\section{Conclusions}

In Albania there are possibilities where is found the positive connection between the potential of the development of the agriculture, the agricultural product and the economic growth of the development of the country, based on the agricultural resources, agroindustry potentially competitive and the human resources, to serve for an economic growth and a sustainable long lasting development.

The weak connections that actually exist between the systems of the agricultural production and the rural and urban markets wholesale and retailing ones and the international markets as well as the problems that exist in the organization and well functioning of the markets, cause a lack of the efficiency and effectiveness in total and the rural markets and the agricultural products wholesale and retailing ones.

The complex problematic of the production of the agricultural products, their processing restoring and the standardization the marketing and the trades and the weak connection between the production,trading and marketing of these products influence each other in the form of cause result cooperation creating a vicious circle ,that prevent the agricultural development and the rural one and the connection between the trade of the agricultural products and the application of the marketing practices and mis marketing in this field.

There are potential possibilities for the strengthening of the connection of the agricultural marketing with the growth of the agricultural production where there possibilities to make it sustainable and to guarantee the simultaneous development between the agricultural marketing and the growth of the agricultural production with the objective to develop with a strong base as a potential support for the economy and the trades at home or export.

\section{Recommendations}

The improvement of the efficiency and the effectiveness of the market as a whole and the rural and the agricultural products wholesale and retailing ones needs connection very strong ones and the development and improvement of the systems of the agricultural production and the rural and urban trades or markets, wholesale and retailing ones the international markets as well as the elimination or the avoidance of the problems that exist in the organization and well functioning of the markets.

The accomplishment of the agricultural policies and food as part of the total policy for the development of the country based on the suitable model of the economy makes it possible not only the elimination but the prevention of the complex problematic of the production of the agricultural products.this makes it possible that the connection between the production ,the commerce and the marketing of these products strengthens and influence for the growth of the production and the application of the mix marketing.

The exploitation of the potential possibilities for the strengthening of the connection of the agricultural marketing and the growth of the agricultural production, the potential possibilities to make it more stable and to guarantee the simultaneous development between the agricultural marketing and the growth of the agricultural production. With the the aim to create a strong agricultural base as a potential support for the economy and the domestic trades and for export and the emerge of the modern agricultural systems that ensure the growth of the production, better possibilities for the improvement of the food structure of the population, the increase of the incomes in the farming level and as a nation in a continuous way.

\section{References}

Agjencia e Nxitjes së Investimeve (ANI) 2005 "Udhëzues për Eksportet, Manual"

Beierlein,J.,Woolverton,M.,Prentice Hall.(1991)."Agribusiness marketing the management perspective"

FAO(1984) "Agricultural Extension, a reference manual"

FAO "Agricultural and Food Policy"

FAO "Analysis of Agricultural and Food Policy"

Knutson, R. D., Penn, J. P and Boehm, W." Agricultural and Food Policy".

Kolnikaj,P.,Vërçuni, A. dhe Male B., "Marketingu i produkteve bujqesore " 
Schiff,M.,Valdes,A.World Bank Comparative Study: "Politika ekonomike e politikës së cmimeve bujqësore Volumi 4, Malone,J. EU / PHARE (1996)"Marketingu i produkteve bujqësore" Manual Meulenberg,M. (1995)"Food and agribusiness marketing in Europe". 